International Journal of English Literature and Social Sciences
Vol-7, Issue-1; Jan-Feb, 2022
Journal Home Page Available: https://ijels.com/
Journal DOI: $10.22161 /$ ijels

Peer-Reviewed Journal

\title{
Adoption of Protected geographical Indication (PGI) for Kenyan Tea
}

\author{
Brian Kipkoech $^{1}$, Vlad llie Isarie ${ }^{2}$
}

${ }^{1}$ Research scholars, Msc. Food Identity, Ecole Supérieure d'Agricultures d'Angers.

${ }^{2}$ Msc. Agribusiness Management, USAMV Cluj-Napoca.

Received: 18 Nov 2021; Received in revised form: 20 Dec 2021; Accepted: 06 Jan 2022; Available online: 13 Jan 2022

(C2021 The Author(s). Published by Infogain Publication. This is an open access article under the CC BY license (https://creativecommons.org/licenses/by/4.0/).

\begin{abstract}
Product recognition is one of the key issues that aid in promoting and protecting its reputation based on the attributable properties possessed by the product. The geographical indication is a pillar that has been developed to protect the uniqueness of these products (its production, know-how and origin). In Africa, full appreciation of GIs has not been achieved, this is due to lack of knowledge of intellectual property rights, their benefits, frameworks, how to register and protect these products, few products, including the Taita basket, have been registered, but most of the products have the potential to be registered as GI, including sweet potatoes from Gabon, cassava from Ghana, coffee from Kilimanjaro (Musungu 2008). Most African farmers still use traditional methods to cultivate, process and preserve different products. In Kenya, legal protection of products is provided by trademarks, but this system does not protect or increase the value of the products in the market. This case study identifies tea from Kenya, which has been marked as to having a unique taste and quality, based on the agro-geo-climatic situations of the region and also the know-how skills possessed by Kenyan tea farmers. It then discusses the possibility of registering Kenyan Tea using European Quality System as a strategy and its role to Kenyan tea growers.
\end{abstract}

Keywords-Geographical Indications, Marketing strategy, Quality marks, Protected Geographical Indication.

\section{INTRODUCTION}

\subsection{Kenyan Tea Sector}

Tea (Camellia sinesis) is a beverage made from the sinesis sp. plant (as opposed to herbal "teas" which are infusions made from plants that have nothing to do with Camellia sinesis). Tea is the world's most consumed drink, after water (Macfarlane, et al 2004). some, like Darjeeling and Chinese greens, have a cooling, slightly bitter, and astringent flavor, while others have vastly different profiles that include sweet, nutty, floral, or grassy notes. Tea has a stimulating effect in humans primarily by its caffeine content (Cappelletti S. et al January 2015). In Kenya, Tea is the main cash crops grown today. It has been the main foreign exchange revenue earner for the country. The major type of tea produced in Kenya is the black tea. However, green tea, yellow tea, and white tea is produced on order by major tea producers.(CPDA, 2008). These farmers live in rural areas where economic opportunities are rare Small-scale producers of tea have not earned the real value of their produce despite the continuous reforms established by the governments. Different strategies in the world have been used to market different agricultural products, some based on the production process some based on the authenticity of the products, Europe have developed and implement a qualitybased system and use it as a tool that help most of the small-scale producers in different regions and is currently being adopted worldwide. This report reviews one of the strategies that can be used to valorize Kenyan tea, and more importantly discuss the need for the adoption of a protected Geographical Indications quality marks in Kenya 
to help the small producers and also protect indigenous products that link to specific places, Community and are in the verge of disappearing because of new and commercialized products that resembles the authentic products. This report purely uses secondary data and different articles related to the topic of discussion.

\subsection{Marketing of Kericho Tea}

The marketing of tea starts from the farm. The farmer has the choice between different potential buyers. This includes private companies, middlemen who buy and sell to processors or the KTDA tea factory. Once processed, the tea is sold locally or internationally through contracts and auctions in Mombasa(CPDA, 2008). Tea from the domestic market is blended, packaged and sold through wholesale and retail channels, while tea from the export market is packaged in 50-70 $\mathrm{kg}$ bags and auctioned in bulk. Mixing and conditioning is usually done outside the country, depending on the different import markets. For example, Pakistan, Egypt and the UK prefer black tea. France prefers green tea, while Germany and the United States of America prefer specialty teas.(Leading \& Countries, 2008).There are barriers to entry into the market, including quality and food safety requirements, standards of consumer conduct, especially towards highend tea markets (KIPPRA, 2017).

\subsection{Objective}

The objective of this case study is to determine the feasibility of adopting European quality mark into a nonEuropean country and the possible impacts it has on a region and to the producers of the product.

\section{REGISTERING KENYAN TEA AS PGI}

\subsection{Legal Framework}

2010/11 Kenyan constitution supports intellectual property rights and protection for example, Art. 69(1) (c) and (e) mandates the State to protect and enhance intellectual property, traditional or indigenous knowledge of biodiversity and the genetic resources of the communities and protect genetic resources and biological diversity.(The Constitution Of Kenya, 2010) Kenya aims to raise incomes in agriculture, livestock and fisheries by processing and thereby adding value to her products before they reach the market. This will be done in a manner that enables producers to compete with the best in other parts of the world. A number of strategies to transform and improve the agricultural and livestock sector will be used. This includes Improving the value gained in the production and supply chain through branding of Kenyan farm products.(Geoffrey M. Ramba, 2016). Kenya is a member of the WTO (Since 1st January 1995(WTO | Kenya -
Member Information, n.d.) and thus a signatory of the TRIPS Agreement (Trade Related Aspects of Intellectual Property Rights). For the purposes of TRIPS Agreement Intellectual Property refers to "All categories of intellectual property that are the subject of Sections 1 through 7 of part II of the Agreement (Article1:2). This includes copyright and related rights, trademarks, geographical indications, industrial designs, patents, integrated circuit layout-designs, and protection of undisclosed information. Kenya has not yet acceded to either of the two international GI agreements (Madrid and Lisbon) concerning the protection of GIs. Only option for mutual protection of GIs with other countries would be bilateral agreements (Geoffrey M. Ramba, 2016).

\subsection{Certifications Existing}

Currently tea products from Kenya are only registered as a trademark,(Njuguna, 2019). each company and factory name their product with the desired name they like, for example kuresoi tea factory name, some kuresoi tea legends and other kuresoi marathon. Certifications bodies include rainforest which is usually a consideration for a company that is seen as compliant to sustainability. ISO 22000: 2005 (Food Safety Management System), fair trade and others. As a result of a favorable geo-agro-climatic conditions within Kenya highlands region, with a specific soil profile, plantation and management protocols, cultural and traditional human practices related to tea and a skilled local workforce, it possesses an incomparable taste, color and high-quality reputation, distinguishing itself from tea in the other regions. This offers a high chance to be registered successfully as one of the GIs products (Monique Bagal et al, 2013). The applicable legal framework is the Trademarks Act, Cap 506, No.51 of 1956, as amended in 2002 and the Trademarks rules, LN575/1956, as amended in 1994 and 2002. (The Constitution Of Kenya, 2010). In Kenya, GIs are protected by trademark laws, which cover certification marks including geographic names.(Geoffrey M. Ramba, 2016) Indeed, Article 12 - (1) - (d) of the Act provides that a trademark with a direct reference to a geographical name does not have sufficient distinctive criteria. This is why certification marks and collective marks can be registered to protect a geographical name. This registration constitutes a brand for ten years from the date of the request. Six months before the expiration of 10 years, holders may apply for renewal of registration. The authority responsible for the registration is the Head of the Intellectual Property Institute of Kenya.(K.I.P.I, n.d.) 


\subsection{Registration of PGI Kericho Tea}

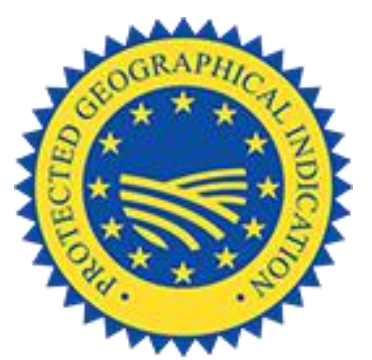

Image 1: showing the PGI Quality mark

PGI is a quality mark designed by the European union as sign given to a product a country, region or locality where the product's particular quality, reputation or other characteristic is essentially attributable to its geographical origin, it is used in agricultural food products and wine. (European Commission, n.d.)

As part of the EU's system of IPRs, names of products registered as GIs are legally protected against imitation and misuse within the EU and in non-EU countries where a specific protection agreement has been signed, nonEuropean product names can also register as GIs if the country of origin has a bilateral or regional agreement with the EU that includes the mutual protection of such names(European Comission, n.d.). An agreement therefore between Kenya Government and European union can be initiated and adopted by the KTDA to register their growers and use the quality mark.

\subsection{Link to Geographical area and Human Kno- how}

All of the tea produced in Kenya are grown in the rift valley highland regions. The tea growing areas in Kenya are broadly sub-divided into two regions defined by the Great Rift Valley. In the east of the Rift Valley tea is grown around the Aberdare Highlands, Mt. Kenya regions and Nyambene Hills, while in the west of the Rift Valley tea is grown in Nandi Hills, Kericho, Mt. Elgon, and Kisii Highlands. Over $60 \%$ of Kenyan tea is produced by about 300,000 smallholder tea farmers managed by the Kenya Tea Development Agency Ltd (KTDA). Brown DR. (2006),

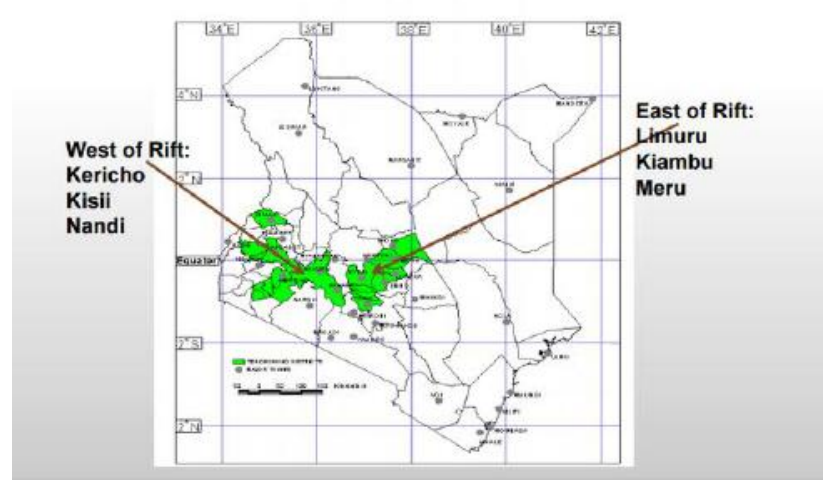

Image 2: Tea plantation in Kenya highlands KTDA 2006

Both rift valley regions in Kenya have the approximate same climatic conditions. During normal climate cycle it receives an average rainfall from 1658 millimeters., temperatures of $1.0^{\circ} \mathrm{C}$,(Eitzinger et al., 2011). The tea growing area has a tropical climate which is influenced by the varied topographic features in the western and central parts of Kenya such as the Great Rift Valley, Lake Victoria, Nandi hills, Aberdares and Mt. Kenya (Leshamta, 2017). Both the areas receive adequate rainfall for the tea production however the availability of the precipitation is not the same, in west of the rift valley it experiences offseason rainfall due to local effects of the influence of the Lake Victoria air mass, Nandi hills and the Congo air mass. The region "es rainfall activities are greatly enhanced whenever the country experiences westerly anomalies in the medium level $(700 \mathrm{mb}$ level) which fetch moisture from the wet Congo basin into the adjacent western part of the country thus allowing the formation of deep convective clouds which precipitate in the form of showers accompanied by thunderstorms and sometimes hailstorm which is a common weather menace in the Kericho tea growing region.(Leshamta, 2017). Furthermore according to Leshamta, (2017), East of the rift valley lies parallel to the Kenyan coastline and its high altitude influences orographic lifting in the "Anabatic" upslope daytime winds which enhances wet weather activities especially whenever the country experiences easterly anomalies at the medium level that fetch moisture from the Indian Ocean into the region different. The common geo-climatic conditions, Kenya's rich, deep reddish soil that has a high mineral content and creates fertile land for the tea bushes to thrive, the high altitude of the sweeping ridges where the tea is farmed has contributed to Kenyan tea having a higher antioxidant content than others, also providing a unique quality including distinct amber brownish colour and what is described as a "brisk", "full bodied" flavor. which refers to a robust flavor that can stand up well with milk, Kenyan tea creates a 
richer infusion than poorer quality tea which can leave you with a light or weak cup of tea.(Williamson Tea, n.d.). Apart from geo-agro-climatic growers of Kenyan tea also have know -how knowledge on the production process that is defined in the growers guides of Tea research and have passed from one generation to another. During plucking of Tea leaves, to maintain the uniformity of the level farmers use a long straight stick. Plucked tea leaves are placed in a traditionally weaved basket made from specific trees. Also, a sack made of sisal which is perforated is used to increase aeration and avoid the scorching of the leaves. Handpicking of leaves one by one with a requirement of two leaves and buds. (Samson et al., 2019)

\section{ECONOMICS OF REGISTRATION OF KENYAN TEA AS A PGI}

The growing demand for and attention to the "qualities" of agri-food products is a result of a range of factors such as the increased awareness of food safety, the socio-cultural status of consuming certain foods and renewed interest in and nostalgia for culinary heritage (Ilberry and Kneafsey (2000). But to access these "quality" products consumers always look for a trusted supplier who will guarantee a continuous supply of healthy food therefore quality based system will always be the alternative for the consumer. Origin-labeled products are an important example of this, as trends in the food sector over the past decade indicate that consumers are increasingly placing value on products they can associate with a certain place and/or special means of production (Ilbery and Kneafsey (1998)). This finding therefore by Llbery and kneafsey show that a certified product will start receiving a boost and recognition in terms of purchases hence an increase in the demand of it. Different number of factors contribute to success of small rural enterprises that target niche markets, these factors mostly include the market access and differentiation this is according to the case study by OECDD (1995) furthermore an approach addressing these factors is to work collectively in order to develop a competitive advantage. Given this, registration of Kenya Tea with a collective quality mark in the market will not only increase the competitiveness but also increase the uniqueness among other competitors, this is in agreement that Geographical indications act as a strong differentiation tool through the creation of collective monopolies. Seemingly a contradiction in terminis, the existence of monopolies consisting of a group of firms was argued by Olsen (1962). Preventing usurpation of origin-based products and protecting the reputation of these products could potentially have a strong developmental impact through an improved income effect. Ultimately this could contribute to increased employment and improved livelihoods. (Bramley et al., 2003) Furthermore a study by Bramley et al. (2003), shows that the GI protection increased the price of Darjeeling tea in total than 1 percent in the real terms over the 1986-2002 period which indicates a very modest price premium effect as a result of GI protection. However, Kenyan tea like Columbia café should focused more on the international market rather than within the local market. This in accordance with the argument by Kerr. (2006), that to raise the benefit of GI protection, producers from developing countries would most cases need to invest significantly in marketing campaigns.

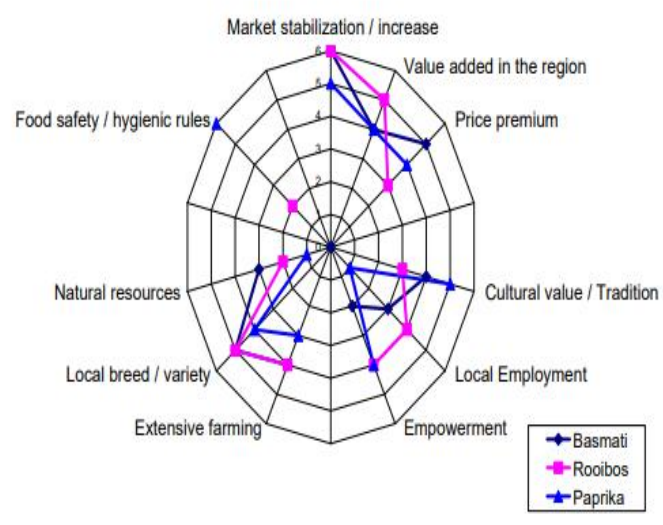

Fig.1 Impacts for established Geographical Indications (Barjolle, 2021)

According to Barjolle (2021), establishment of GI will have an impact on the market stabilization, value addition to the product and other factors. If Kenyan tea will be registered as GI tea, the agro-tourism sector will also be boosting, given that the highland regions have different landscape which often attract tourist.

\section{CONCLUSION}

From different case studies cited, it is possible to register Kenyan highland tea as a GI using the European quality label, as far as a bilateral agreement between the Kenya Government and European union. It is beneficial for both the states to protect their products especially agricultural products which are prone to usurpation.

Registration of PGI quality mark will be a unique strategy that will put Kenyan tea into a better place than the rest of East African countries producing tea. Furthermore, it will be a competitive strategy that will also set apart itself from the rest of the world tea market. Kenyan tea will be competing based on quality rather than the quantity and as 
the world incline towards healthier and quality assured products Kenyan tea will be among the most sorted.

Geographical Indications will not only focus on improving the price or as a market strategy but also come with other benefiting factors including better production method which are ecofriendly and are more sustainable, also rural development and agrotourism will benefit from the registration of Kenyan tea.

Establishment of protected geographical indication PGI to Kenyan tea will also come with milestones, Kenya being one of the developing nations faces different structural and legal challenges. Protections and control of registration will be a major problem given that there is no legal framework or independent institution that will guarantee clear and transparent control system.

\section{ACKNOWLEDGEMENT}

We would like to express our special thanks of gratitude to our professors as well as our colleagues of Master Food Identity who shared with us knowledge and skills especially relating to this topic of GIs. Special appreciation to the team for strong collaboration during this writing period.

\section{REFERENCES}

[1] Bagal, M. N., Belletti, G., Marescotti, A., \& Onori, G. (2013). Study on the potential of marketing of Kenyan Coffee as Geographical Indication: Case study related to the study on the potential for marketing agricultural products of the ACP countries using geographical indications

[2] Barjolle, D. (2021). Impacts of Geographical Indications Review of Methods and Empirical Evidences Impacts of Geographical Indications Review of Methods and Empirical Evidences. January 2009.

[3] Bramley, C., Biénabe, E., \& Kirsten, J. (2003). the Economics of Geographical Indications: Towards a Conceptual Framework for Geographical Indication Research in Developing Countries. 109-149.

[4] Brown DR (2006), Livelihood strategies in the rural Kenyan highlands. Cornell University

[5] Cappelletti, S., Piacentino, D., Daria, P., Sani, G., Aromatario M (2015). "Caffeine: cognitive and physical performance enhancer or psychoactive drug?". Current Neuropharmacology.13(1):71-88.

Doi:10.2174/1570159X13666141210215655. PMC 4462044. PMID 26074744.

[6] CPDA. (2008). REPORT ON SMALL-SCALE TEA SECTOR Christian Partners Development Agency ( CPDA ) Together in Development. Development, March.

[7] Eitzinger, A., Laderach, P., Quiroga, A., Pantoja, A., \& Gordon, J. (2011). Future Climate Scenarios for Kenya' s Tea Growing Areas. 1-27.
[8] European Commission. (n.d.). Geographical indications European Commission. Retrieved January 2, 2022, from https://ec.europa.eu/info/food-farming-fisheries/food-safetyand-quality/certification/quality-labels/quality-schemesexplained_en\#geographicalindications

[9] Geoffrey M. Ramba. (2016). Policy Framework for Promoting GIs In Kenya . Protection of Intellectual Property under the New Constitution in Kenya .

[10] K.I.P.I. (n.d.). Period of protection. Retrieved January 2, 2022, from https://www.kipi.go.ke/index.php/period-ofprotection

[11] Leading, S., \& Countries, P. (2008). Sustainability Issues in the Tea Sector.pdf (Issue June).

[12] Leshamta, G. T. (2017). Assessing The Suitability Of Tea Growing Zones Of Kenya Under Changing Climate And Modeling Less Regret Agrometeorological Options. http://erepository.uonbi.ac.ke/handle/11295/102192\#.YWm 2RnJFyaM.mendeley

[13] Macfarlane, A., and Macfarlane, I. (2004). The Empire of Tea. The Overlook Press. p. 32. ISBN 978- 1-58567-493-0.

[14] Musungu, S.F. (2008), the protection of geographical indications and the Doha round: Strategic And Policy Consideration For Africa, QUNO, IP Issues Paper No. 8.

[15] Njuguna, E. (2019). NATIONAL WORKSHOP ON IP FOR INNOVATIVE AND. June.

[16] Kerr, W.A., 'Enjoying a Good Port with a Clear Conscience: Geographic Indicators, Rent Seeking and Development', The Estey Centre Journal of International Law and Trade Policy, 7 (1): 1-14, 2006.

[17] Samson, kamunya, Ochanda, S., Cheramgoi, E., Chalo, R., Sitienei, K., Muku, O., Kirui, W., \& Bore, J. K. (2019). Tea Growers Guide.

[18] THE CONSTITUTION OF KENYA, 2010. (2010). Laws of kenya. The Constitution of Kenya, February, 191.

[19] Williamson Tea. (n.d.). Why is Kenyan tea different? Williamson Tea. Retrieved January 3, 2022, from https://www.williamsontea.com/bush-to-cup/kenyan-teadifferent/

[20] WTO | Kenya - Member information. (n.d.). Retrieved January 2, 2022, from https://www.wto.org/english/thewto_e/countries_e/kenya_e. htm 